\title{
SARCOIDOSIS IN CHILDREN
}

\author{
Edwin L. Kendig, JR., M.D. \\ EDWARD J. Wiley, M.D.
}

From the Department of Pediatrics and the Child Chest Clinic, Medical Colleg of Virginix Hospital, Richinond, Virginia, U.S.A.

APPARENTLy, sarcoidosis is relatively rare among children. In a review of world literature to February 1953, McGovern and Merritt (1956) found only 104 cases in children under 15 years of age. To these, they added nine others, all diagnosed in Washington hospitals. Undoubtedly, there are many other cases of recognized sarcoidosis in children still unreported, but it seems apparent that the disease is relatively rare in this age group.

Excluding two patients with doubtful diagnosis, only seven proved cases of sarcoidosis in children under I 5 years of age have been observed at the Medical College of Virginia Hospitals. Most noteworthy, however, is the fact that three cases occurred in siblings, a condition which, as far as we can determine, has not elsewhere been reported.

Comparison of those patients diagnosed at the Medical College of Virginia Hospitals (Richmond series), with the nine cases reported by McGovern and Merritt (Washington series) and the cases culled from the literature by the same authors reveals some interesting data.

While study of the literature reveals that the youngest reported patient with sarcoidosis, proved by biopsy, was a 2-month-old male, most of the patients seen in childhood are in the older or adolescent age group. Of the 104 cases reported in the literature (Table $\mathrm{I}), 77(74 \%)$ were between the ages of 9 and 15 years. All of the seven Richmond cases and eight of the nine in the Washington series were in this age group. It must be noted that consideration should be given to the possibility that diagnosis may have been delayed because of the mild or insidious onset or the tendency of the disease toward regression.

Of the above 104 cases from the world literature, race was stated for 87 , of whom 63 were white and 24 negro. All cases in both the Washington and Richmond groups were negroes (Table 2).

The material included in this paper was presented in part at the International Conference on Sarcoidosis in Washington, D.C., Fune 1-3, 1960. It will be included in publication of the transactions of that meeting.
While only two of the reported ro4 cases $\overrightarrow{\vec{\omega}}$ occurred in the same family, our group includes $\stackrel{\circ}{\circ}$ three siblings. There were no siblings amongo the Washington patients (Table 3 ).

It is interesting, too, to compare clinical mani-w festations. Cummings, Danner, Schmidt and Barnwell (1956) noted involvement of the lung and $/ \stackrel{\omega}{N}$ or hilar lymph nodes in $96 \%$ of adult cases, while 0 only $54(52 \%)$ of the 104 cases in children were so affected. The Washington and Richmond groups more closely resemble the adults reported $\vec{P}$ by Cummings, in that eight of the nine in the former and all seven in the latter group showed such involvement (Table 4).

Peripheral lymphadenopathy was present in of the ro4 world cases and in six of nine (Washing-ब ton) and four of seven (Richmond) local cas ; respectively.

Skin lesions in children are relatively common (5 I of 104 cases from world literature) and there was involvement in six of the Washington and two of the Richmond series.

While eye lesions also occurred in $49 \%$ of the $\overrightarrow{\vec{B}}$ world group, practically all were minor ones. In 3 contrast, one of the four cases noted in the Washington series and two of the four in the Richmond group resulted in partial blindness.

None of the local groups showed the syndrome. of uveoparotid fever, while this occurred with 3 relative frequency in the world series $(27 \%)$. On the other hand, bone involvement occurred with approximately the same frequency in the world group (30 of 104 cases) and the Washington? series (three of nine cases), but was present in only음 one of seven Richmond patients.

Liver and splenic enlargement was noted in two N of the seven Richmond cases.

It will be seen, then, that our group of cases closely parallels that reported by McGovern and ${ }^{\omega}$ Merritt, and differs considerably from that cullede from the world literature. All cases in both the former groups were negroes, and practically all ${ }_{S}^{\infty}$ were in the older age group. Hilar lymph node ${ }^{+}$ involvement was almost always present, the syndrome of uveoparotid fever did not occur, eye्बे 
TABLE I

AGE

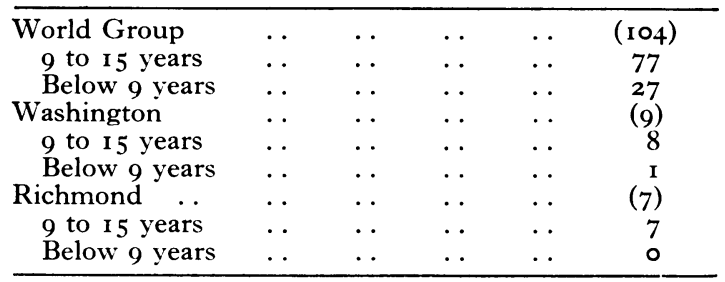

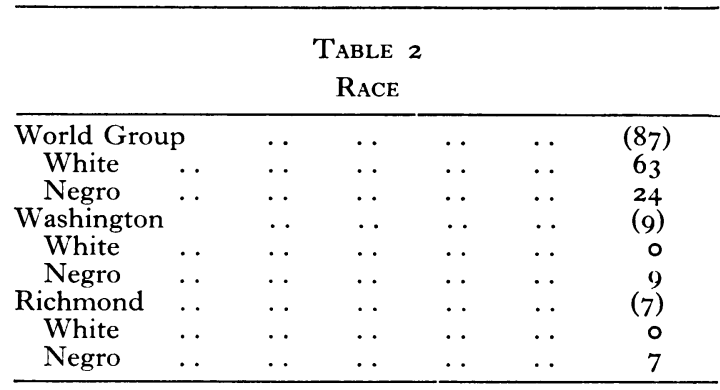

TABLE 3

Siblings

\begin{tabular}{llll|c|c}
\hline & & & & Cases & Siblings \\
\cline { 5 - 5 } & & \\
World Group & $\ldots$ & $\ldots$ & $\ldots$ & 104 & 2 \\
Washington & $\ldots$ & $\ldots$ & $\ldots$ & 9 & 0 \\
Richmond.. &. &. & $\ldots$ & 7 & 3 \\
\hline
\end{tabular}

lesions were frequently present and those eye lesions of serious nature were noted in three instances, one in the Washington group and two in the Richmond group.

Diagnosis was corroborated in all our patients and in eight of the nine cases reported by McGovern and Merritt by means of lymph node biopsy, and tuberculin reaction was always negative.

Although McGovern and Merritt agree that there is usually ' an absolute increase in serum globulin, so that the albumin-globulin ratio is frequently reversed ', they make no detailed report of laboratory findings in their patients. Our group showed hyperglobulinæmia in six of seven cases (Table 5). Serum calcium elevation (above I I $\mathrm{mg}$. per IOO $\mathrm{ml}$. of serum) was present in two and alkaline phosphatase higher than five Bodansky units in only one of five tested cases.

Next to hyperglobulinæmia, the most consistent laboratory finding was eosinophilia (above $4 \%$ ). This occurred in four of seven cases, and two of these cases showed eosinophilia above $7 \%$. Leukopenia below 5,000 was noted in two of the seven cases.

Elevation of erythrocyte sedimentation rate was noted in four cases.

Finally, a suggestion as to epidemiology of the
TABLE 4

Organs AfFected

\begin{tabular}{|c|c|c|c|}
\hline & $\begin{array}{c}\text { Reported } \\
\text { World } \\
\text { Cases } \\
(\text { IO4) }\end{array}$ & $\begin{array}{l}\text { Washington } \\
\text { Series (9) } \\
\text { McGovern } \\
\text { and Merritt }\end{array}$ & $\begin{array}{l}\text { Richmond } \\
\text { Series (7) }\end{array}$ \\
\hline $\begin{array}{l}\text { Peripheral } \\
\text { lymphadeno- } \\
\text { pathy }\end{array}$ & 32 & 6 & \\
\hline $\begin{array}{l}\text { Lungs (paren- } \\
\text { chyma hilar } \\
\text { nodes) }\end{array}$ & . & 8 & 4 \\
\hline $\begin{array}{ll}\text { Skin } & \ldots \\
\text { Skins } & \ldots\end{array}$ & $\begin{array}{l}54 \\
5 \mathrm{I}\end{array}$ & $\begin{array}{l}8 \\
6\end{array}$ & $\begin{array}{l}7 \\
2\end{array}$ \\
\hline Eyes .. $\quad \ldots$ & $5 \mathrm{I}$ & 4 & 4 \\
\hline $\begin{array}{l}\text { Bones.. } \\
\text { Uveoparotid }\end{array}$ & 30 & 3 & I \\
\hline fever & 28 & 0 & 0 \\
\hline Liver & 13 & 3 & 2 \\
\hline Spleen & 24 & $\mathbf{I}$ & 2 \\
\hline
\end{tabular}

TABLE 5

Laboratory STUdies (RICHMOND)

\begin{tabular}{llcl|c|c}
\hline & & & $\begin{array}{c}\text { Cases } \\
\text { Tested }\end{array}$ & Present \\
\hline Hyperglobulinæmia & $\ldots$ & $\ldots$ & 7 & 6 \\
Hypercalcæmia &. &. & $\ldots$ & 5 & 2 \\
Elevated alkaline & phosphatase & $\ldots$ & 5 & I \\
Eosinophilia &. & $\ldots$ & $\ldots$ & 7 & 4 \\
Leucopenia &. &. &.. & 7 & 2 \\
\hline
\end{tabular}

disease should be noted. The three cases occurring in siblings under I $_{5}$ years of age, mentioned earlier in the discussion, live in Nansemond County, Virginia. One of the other four Richmond cases is also from Nansemond County and one from the adjoining county of Southampton. In this area, the chief crop is peanuts and a large number of inhabitants either work in the peanut fields or in peanut factories.

Investigation discloses that the Health Department of Nansemond County, with a population of approximately 38,000 , has on file about 50 cases (practically all of whom are adults) in which a presumptive diagnosis of sarcoidosis has been made. Actually, in this county and the two adjoining counties of Southampton and Isle of Wight, there are more than Ioo such cases with suspicious X-rays.

It is true that pine trees grow in abundance in this same section, but the heavy concentration of presumptive cases in this small area would seem to indicate the presence of some other factor. Whether or not peanut dust plays a role is problematical. However, there is some information to the effect that the peanut growers have long been aware of some sort of chronic lung ailment which may result in those working in peanut factories. Further, a great deal of this dust must be shaken from the vines when peanuts are 
harvested, and thus even those who are not factory workers may be exposed to the dust.

At the present time, a survey of sarcoidosis in this area is underway. The first effort will be directed toward the establishment of unequivocal diagnosis in the suspected cases. From that, it is hoped that a community survey and then an epidemiologic study will follow.

\section{Summary}

It must still be considered that sarcoidosis occurs with relative infrequency in children. Patients reported from the Washington-Richmond area differ from those found in the world literature in that all those in the former groups were negroes, and practically all showed hilar lymph node adenopathy; eye lesions, often of serious nature, were frequently noted. It is suggested that peanut dust may in some way be implicated in the causation of sarcoidosis, occurring in the Nansemond County area of Virginia.

\section{REFERENCES}

McGovern, J. P., and Merritt, D. M. (1956): Sarcoid osis in Childhood, Advanc. Pediat., 8, 97.

Kendig, E. L., JR., and PeAcock, R. L. (1959): Sarcoid osis (Report of Three Cases in Siblings Under Fifteen Years of Age), New Engl. F. Med., 260, 962.

Cummings, M. M., Danner, E., Schmidt, H. H., Jr., and Barnwell, J. B. (1956): Concepts of Epidemiology of Sarcoidosis, Postgrad. Med., 19, 437.

\section{Dr. D. G. James, M.D., M.R.C.P. (Physician, the Royal Northern Hospital)}

The diagnosis of sarcoidosis is a combination of two factors: the compatible clinical picture and histological confirmation. One without the other is insecure; if you get a clinical picture alone it's not sufficient because pulmonary mottling or iritis or other skin lesions can be mimicked by many other conditions, so that one always wants to have histological confirmation. Histological evidence of sarcoid tissue alone, on the other hand, is insufficient, because sarcoid tissue, a granulomatous reaction, is non-specific and can be found, for instance in a liver biopsy and can be due to brucellosis or tuberculosis or fungus infection as well as sarcoidosis.

I want to present a brief review of the incidence in the general population. In this area in Virginia it works out at 50 cases in 38,000 , i.e. something like 140 per 100,000 . Now in a preliminary survey by Dr. Brett the incidence by miniature mass-radiography is roughly 20 per 100,000; but if he splits it up and works out the incidence in Irish women it is 220 per 100,000 and about I10 per 100,000 for Irish men. It is difficult, of course, to be certain of this incidence because in the recent Washington Conference certain amusing results came to light from epidemiological surveys. It was found to be extremely common in the north island of Japan but that is because the medical school in Tokyo attracts all the cases there. In Denmark one of the Danes at the Conference mapped out areas of incidence of sarcoidosis hoping to link it with the pine pollen but he found that the concentration of the disease was practically confined to one area in
North Jutland where there was a tremendous amount. The reason was that there was a man doing an M.D. thesis in that area so all round there the cases were growing up under his eyes and I am quite sure that, now that you have got your teeth into the problem, you are going to uncover a lot more cases in Nansemond County and perhaps there will be a disproportional concentration. Now a point or two about some of the etiological factors. No one knows the cause of sarcoidosis so anyone's guess is as good as anyone else's. I think one should split up the constitutional-racialpregnancy factors, factors in the patient himself, and regional factors. I am sure that there is a constitutional factor; that is well known in the U.S.A. where the incidence in the negroes is 16 times that in the white population. The same type of difference is seen in the U.K. where there is a much greater concentration among the Irish. It is associated with pregnancy and other hormonal factors, sometimes with injections of hormones, and I want to make the point there that most of the children's cases occur in the adolescent period12 to 15-rather than before. I think an endocrinologist would find this worth taking upcertainly from the endocrine point of view, not only with regards to the abnormal calcium metabolism but these other features also.

Now you add to these factors regional ones, and Martin Cummings has brought up his pine-pollen theory for a certain belt. In Georgia there was a beautiful matched-control series of cases of sarcoidosis done by Dr. Comstock and the thing that came out most clearly in the sarcoidosis cases 
was that clay-eating was twice as common. So Dr. Comstock in Georgia feels that clay-eating is a factor in his sarcoidosis cases. I think that those regional factors are probably significant: the peanut dust in Richmond, the pine-pollen in Florida, the clay-eating in Georgia. For after all, if you look at erythema nodosum there are certainly regional factors there. If you are a doctor in the San Joachim valley of California, the commonest cause of erythema nodosum is coccidiomycosis, and if you are on the banks of the Mississippi or in Ohio probably it is histoplas- mosis, and in Africa the commonest cause is leprosy, particularly in the days of sulphone treatment. If you are a doctor in New York and you see erthyema nodosum then it is commonly in the Puerto Ricans that migrate to New York, just as probably in London you will see it most commonly in Irish women who have been living here a year or two. So I throw open those two factors so that there may be a growing point from this in your own practices and your disciplines of sarcoidosis.

\section{Cr. R. M. E. Seal, M.R.C.P. (Pathologist, Sully Hospital, South Wales)}

I want to emphasize what little right I have to be here: I admit never having seen, or at any rate, never having recognized a case of sarcoidosis below the age of 12 ; I thought my colleagues in Sully Hospital could come to my aid and to my consternation they also had not recognized a case of sarcoidosis in this age group. But we have at least a knowledge of erythema nodosum in children with hilar lymphadenopathy, so perhaps I might clarify some of the difficulties in this so-called ' histological confirmation' of the diagnosis of sarcoidosis. Perhaps the best thing to do would be to show a few slides. This (Fig. I) is the picture taken as typical of sarcoid: a lymph node which was enlarged, looked pale and fleshy, with no evidence of caseation macroscopically, and which when seen microscopically consists of ' tubercles' of epithelioid cells and giant cells; the tubercles tending to remain discrete with no definite areas of necrosis. But one does see cases of sarcoidosis which the clinician quite correctly marries with the microscopic picture to make a diagnosis of sarcoid; that is a negative Mantoux with clinical features which we accept as part and parcel of the disease. In some of these one often has to allow some necrosis in the centre of the epithelioid lesion, and in other cases, indeed, one has to press it even further and allow a certain confluence and small areas which most pathologists would consider to be areas of caseation (Fig. 2). In such cases one should always look for acid-fast bacilli, and if possible have a portion of the unfixed tissue for culture and animal inoculation.

The next slide (Fig. 3) illustrates a lymph node from a patient with tuberculosis. A lymph node near this was caseous and this one is a node a few stations up the line. Again we see tubercles without any evidence of necrosis, so this is a pitfall. I think we can say definitely that if a pathologist is given a large lymph node and has to distinguish between sarcoid and tubercle, that when such an enlarged node is non-caseous macroscopically and he can find no areas of caseation microscopically then it is almost certainly not tuberculosis, because we have seen, in Sully Hospital, a large number of these enlarged lymph nodes in primary tuberculosis scooped out; we can grow tubercle bacilli every time, and there has always been macroscopic let alone microscopic caseation, though isolated fields of epithelioid tubercles are easy to find. If the pathologist is given an enlarged lymph node and it is entirely noncaseous it is very unlikely to be tuberculous. The surgeons tell me that this so-called 'hypertrophic tubercle' does occur: all I can say is that I have yet to see it. I have always been able to find macroscopic, and certainly large microscopic, areas of caseation in the enlarged nodes of primary tuberculosis.

The next slide (Fig. 4) illustrates the difficulty if one is given a small portion of lung. This is a patient whom the clinician and the pathologist together could feel perfectly happy was a case of sarcoid. Again we see epithelioid tubercles without any central necrosis.

The next slide (Fig. 5) is a lung biopsy from a child whom we know had a segmental lesion in primary tuberculosis because the lymph node was obviously caseous and grew tubercle bacilli, and the gastric aspirates were positive. The segmental bronchus was perforated by a caseous node, but the lesion itself was grey, with the lobular markings distinct due to thickening of the interlobular septa. When we look at the histology of the lung we see some alveoli full of protein-rich cedema fluid and an occasional macrophage, and tubercles-epithelioid tubercles--surrounded by lymphocytes without any evidence of necrosis 


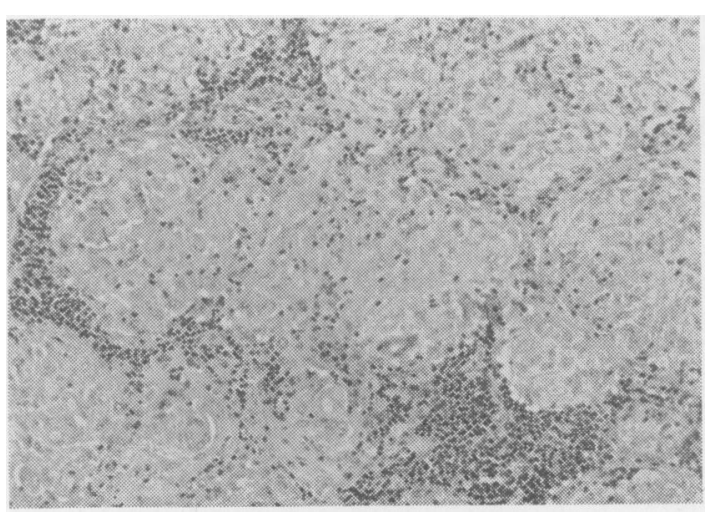

FIG. I.

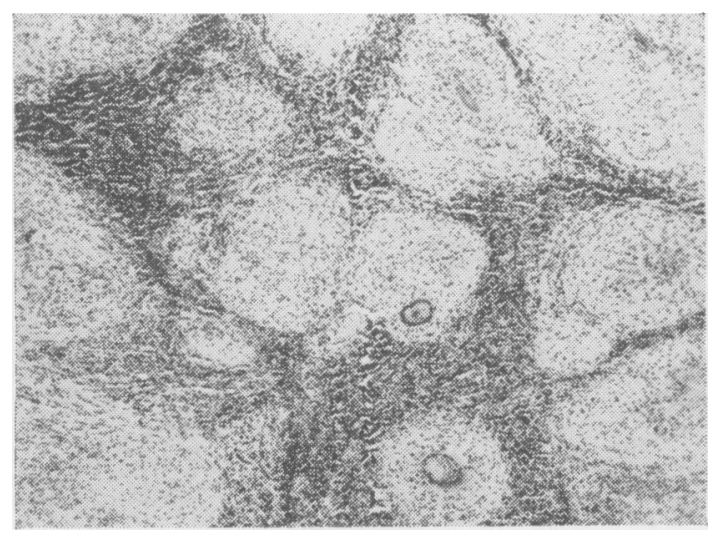

FIG. 3.

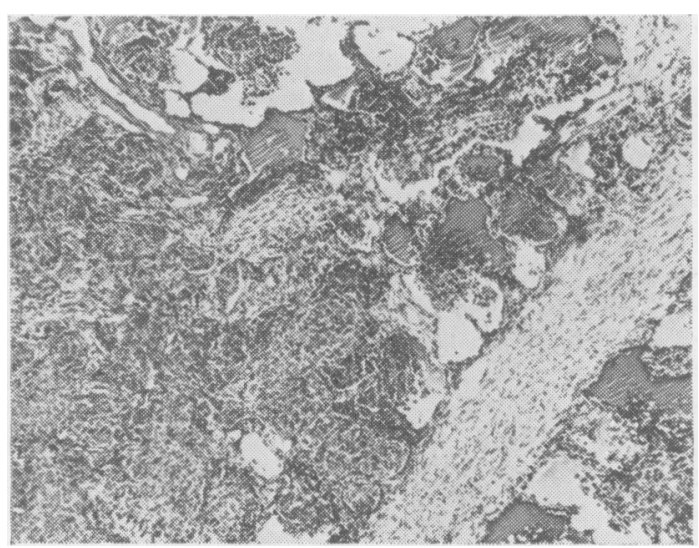

FIG. 5 .

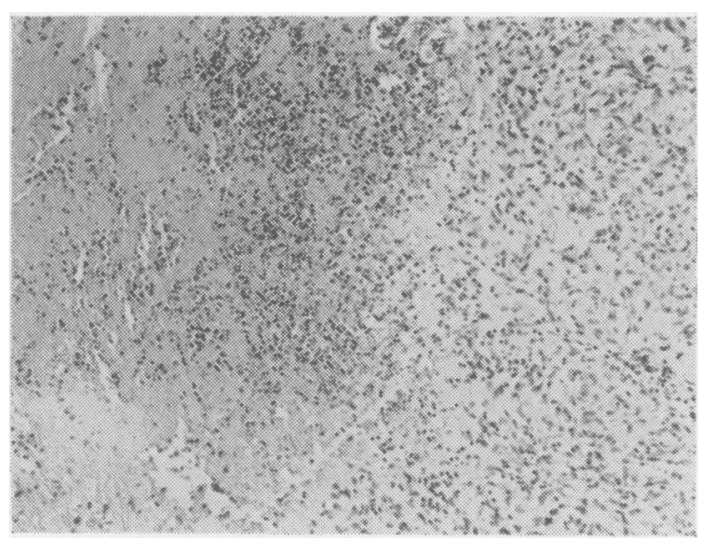

FIG. 2.

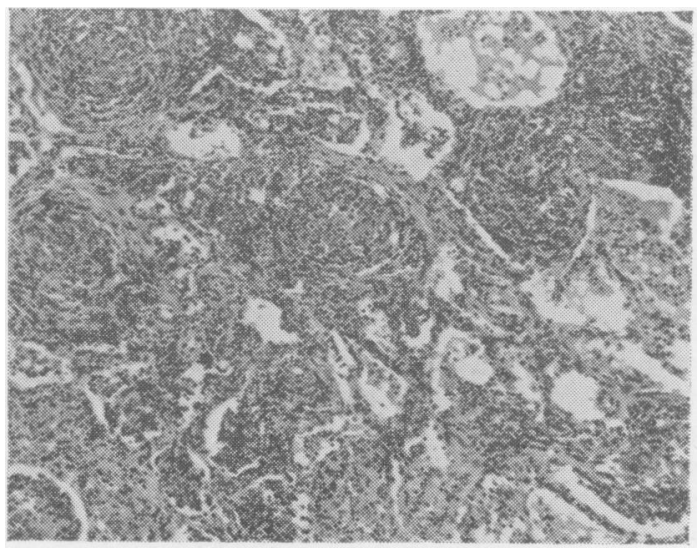

FIG. 4

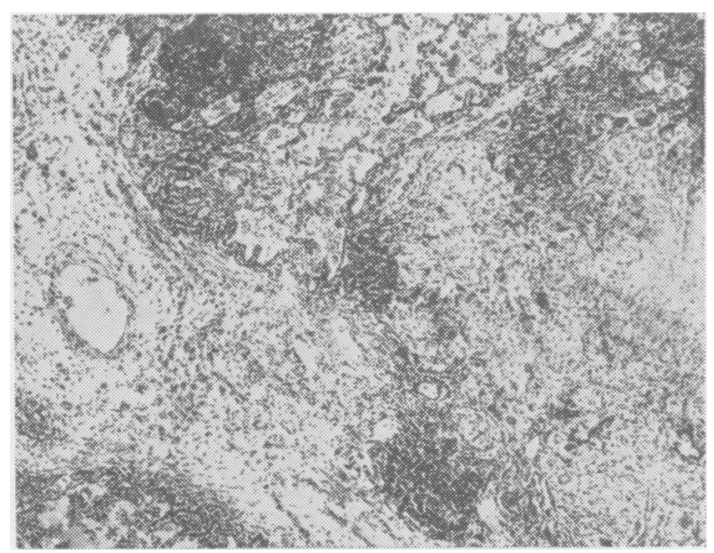

FIG. 6. 


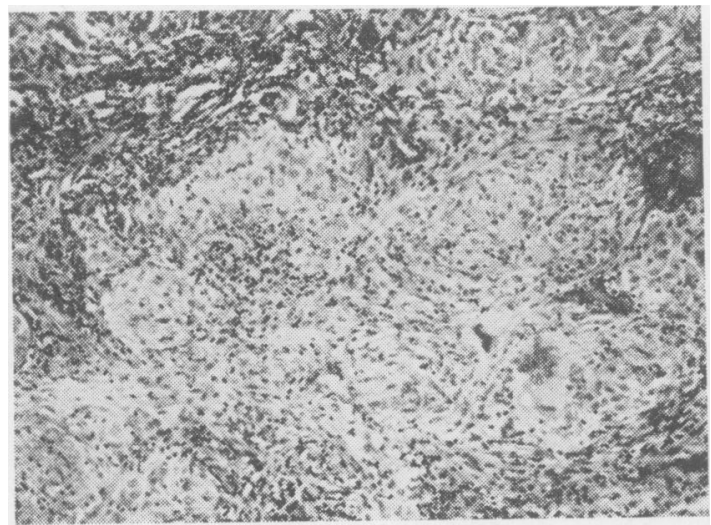

FIG. 7 .

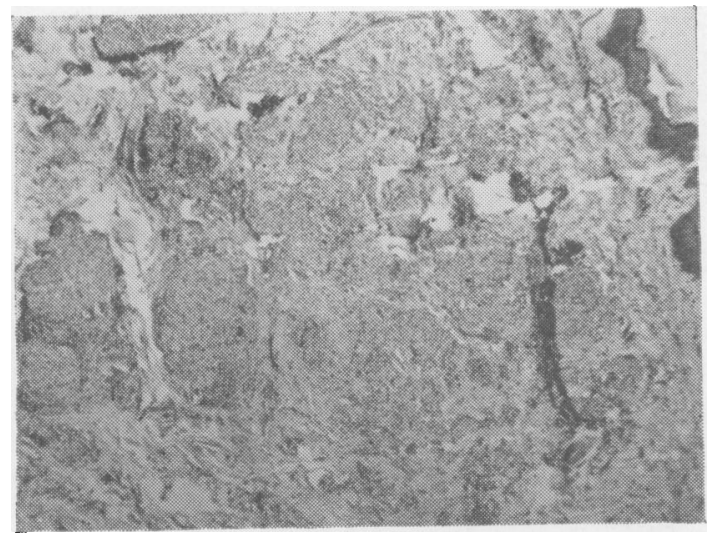

FIG. 9.

whatsoever. So if the pathologist were given this in an M.D. exam as a slide for diagnosis and he had stuck to the criteria for diagnosing sarcoid, this he would-almost certainly-call sarcoidosis. But it is not.

The next slide (Fig. 6) is another example of a segmental lesion in primary tuberculosis with several tubercles remaining discrete, surrounded by lymphocytes without any necrosis.

The next slide (Fig. 7) is an example in a boy aged 15 who had helped with threshing on a farm, and who developed an illness which no one would confuse with sarcoidosis, but radiologically there was a fine miliary mottling without hilar node enlargement. Many people would include sarcoidosis in the differential diagnosis on the radiograph alone. The lung biopsy shows epithelioid tubercles surrounded by lymphocytes. Again, the pathologist, given this in isolation, might conclude he was dealing with a case of sarcoid-

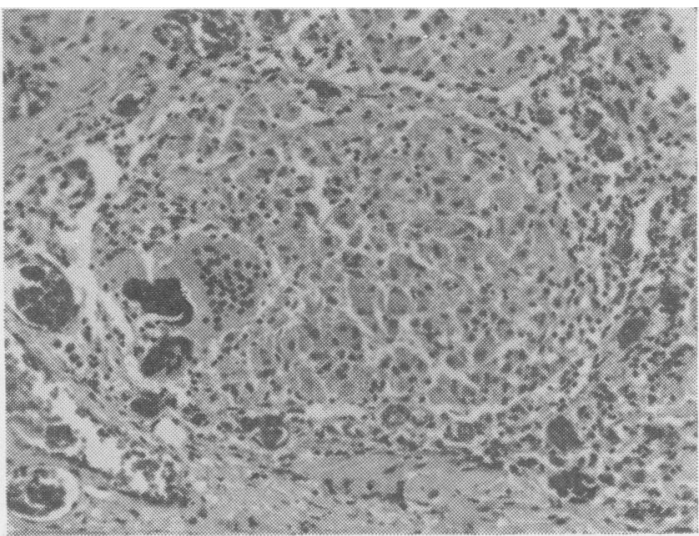

Fig. 8 .

but it is an example of the acute or progressive stage of farmer's lung.

The next slide (Fig. 8) is an area of lung in long standing sarcoid with Shaumann bodies and giant cells. These Schaumann bodies are certainly common in sarcoid but they are also seen in many other conditions. Asteroid bodies likewise were once thought to be pathognomonic of sarcoid. They have also been shown to occur in other conditions.

The next slide (Fig. 9), I think, brings us to perhaps the one criterion on which the histologist and clinician can place great emphasis and that is - the Kveim test. After the intradermal injection of known-active Kveim antigen, a node develops which microscopically consists of several epithelioid tubercles; the interesting thing here is that we find a paradox; in many cases there are obvious areas of necrosis. A good positive Kveim has confluence of the tubercles and areas of necrosis, which a histopathologist might well conclude on histology alone to represent a case of tuberculosis of the skin.

To summarize, I would like to make a plea to clinicians not to lay on pathologists the onus of making the diagnosis of sarcoid. We have seen that small areas in an enlarged tuberculous node and other remote nodes in tuberculosis, may consist of non-caseating tubercles, also that sarcoid tissue may contain small microscopic areas of necrosis. We also all know of local sarcoid reactions with the histology of sarcoid due to other causes, and that epithelioid tubercles occur in liver and in bronchial sub-mucosa in tuberculosis. So that all the pathologist can do is to confirm the presence of a giant cell granulomatous process consistent with sarcoidosis in a patient suspected of sarcoidosis clinically. I wince at the statement-sarcoid, 'proven by biopsy'. 